\title{
Bioprospecção e caracterização de bactérias produtoras de celulase a partir do solo do Cerrado brasileiro
}

\author{
Bioprospection and characterization of cellulase-producing bacteria from Brazilian Cerrado soil \\ Bioprospección y caracterización de bacterias productoras de celulasa del suelo del Cerrado \\ brasileño
}

Recebido: 21/06/2021 | Revisado: 27/06/2021 | Aceito: 30/06/2021 | Publicado: 13/07/2021

\author{
Bianca Aguiar Alves \\ ORCID: https://orcid.org/0000-0002-9544-4100 \\ Universidade Federal do Triângulo Mineiro, Brasil \\ E-mail: biaaguiar13@gmail.com \\ Isabela Sguilla Rotta \\ ORCID: https://orcid.org/0000-0001-7366-6573 \\ Universidade Federal do Triângulo Mineiro, Brasil \\ E-mail: sguillaisabela@gmail.com \\ Alessandra Barbosa Ferreira-Machado \\ ORCID: https://orcid.org/0000-0003-3972-7576 \\ Universidade Federal de Juiz de Fora, Brasil \\ E-mail: alessandra.machado@ufjf.br \\ Aline Dias Paiva \\ ORCID: https://orcid.org/0000-0003-4234-8892 \\ Universidade Federal do Triângulo Mineiro, Brasil \\ E-mail: aline.paiva@uftm.edu.br
}

\begin{abstract}
Resumo
Este trabalho descreve a bioprospecção e a caracterização de bactérias produtoras de celulase isoladas de solo obtido em uma região preservada do bioma Cerrado, em Uberaba, Brasil. A atividade celulolítica foi confirmada em 14 das 84 linhagens bacterianas isoladas. De acordo com a quantificação enzimática, cinco isolados foram selecionados como os melhores produtores de celulase e com base no sequenciamento parcial do gene 16S rRNA foram identificadas como Bacillus siamensis (isolado AB-9; 5.000U/mL), Bacillus toyonensis (isolado AB-1; 4.630U/mL), Bacillus methylotrophicus (isolados MB-3; 4.236U/mL e MP-7; 4.282U/mL) e Bacillus drentensis (isolado ME-2; 4.444U/mL). O extrato enzimático obtido de B. siamensis AB-9 foi o mais estável em diferentes valores de $\mathrm{pH}$ (2-8), mantendo sua atividade celulolítica, enquanto B. toyonensis AB-1 e B. methylotrophicus MP-7 produziram celulases com atividade máxima em $\mathrm{pH} 7$ e 8 . As celulases produzidas por B. siamensis AB-9 e B. toyonensis AB-1 apresentaram alta atividade enzimática em todas as temperaturas analisadas $\left(10-80^{\circ} \mathrm{C}\right)$, enquanto as celulases de $B$. methylotrophicus MB-3 apresentaram atividade máxima na faixa de $20-70^{\circ} \mathrm{C}$. Até o momento, esta é a primeira vez que bactérias produtoras de celulase isoladas do bioma Cerrado brasileiro na região do Triângulo Mineiro com potencial aplicação biotecnológica são descritas.
\end{abstract}

Palavras-chave: Screening; Enzima; Bacillus; Biotecnologia.

\begin{abstract}
This work describes the bioprospection and characterization of cellulase-producing bacteria isolated from the soil obtained in a preserved region of the Cerrado biome, in Uberaba, Brazil. Cellulolytic activity was confirmed in 14 of the 84 bacterial strains isolated. According to enzymatic quantification, five strains were selected as the best cellulase producers, and based on the partial sequencing of the 16S rRNA gene the strains were identified as Bacillus siamensis (isolate AB-9;5.000U/mL), Bacillus toyonensis (isolate AB-1;4.630U/mL), Bacillus methylotrophicus (isolates MB$3 ; 4.236 \mathrm{U} / \mathrm{mL}$ and MP-7;4.282U/mL), and Bacillus drentensis (isolate ME-2;4.444U/mL). The enzymatic extract obtained from $B$. siamensis AB-9 was the most stable in different $\mathrm{pH}$ values (2-8), maintaining its cellulolytic activity, while $B$. toyonensis AB-1 and B. methylotrophicus MP-7 produced cellulases with maximum activity at $\mathrm{pH} 7$ and 8 . The cellulases produced by $B$. siamensis AB-9 and B. toyonensis AB-1 showed high enzymatic activity at all temperatures analyzed $\left(10-80^{\circ} \mathrm{C}\right)$, while $B$. methylotrophicus $\mathrm{MB}-3$ cellulases had maximum activity in the range of $20-70^{\circ} \mathrm{C}$. To our knowledge, this is the first time that cellulase-producing bacteria isolated from Brazilian Cerrado biome in the region of Triângulo Mineiro with potential biotechnological application are described.
\end{abstract}

Keywords: Screening; Enzyme; Bacillus; Biotechnology. 


\begin{abstract}
Resumen
Este trabajo describe la bioprospección y caracterización de bacterias productoras de celulasa aisladas de suelo obtenido en una región preservada del bioma Cerrado, en Uberaba, Brasil. Se confirmó la actividad celulolítica en 14 de las 84 cepas bacterianas aisladas. De acuerdo con la cuantificación enzimática, se seleccionaron cinco aislamientos como los mejores productores de celulasa y en base a la secuenciación parcial del gen rRNA 16S se identificaron como Bacillus siamensis (aislado AB-9; 5,000U/mL), Bacillus toyonensis (aislado AB-1; 4.630U/mL), Bacillus methylotrophicus (aislados MB-3; 4.236U/mL y MP-7; 4.282U/mL) y Bacillus drentensis (aislado ME-2; 4.444U/mL). El extracto enzimático obtenido de B. siamensis AB-9 fue el más estable a diferentes valores de pH (28), manteniendo su actividad celulolítica, mientras que B. toyonensis AB-1 y B. methylotrophicus MP-7 produjeron celulasas con máximos actividad a $\mathrm{pH} 7$ y 8. Las celulasas producidas por B. siamensis AB-9 y B. toyonensis AB-1 mostraron alta actividad enzimática a todas las temperaturas analizadas $\left(10-80^{\circ} \mathrm{C}\right)$, mientras que las celulasas de $B$. methylotrophicus MB-3 mostró una actividad máxima en el rango de $20-70^{\circ} \mathrm{C}$. Hasta el momento, esta es la primera vez que se describen bacterias productoras de celulasa aisladas del bioma del Cerrado brasileño en la región del Triângulo Mineiro con potenciales aplicaciones biotecnológicas.
\end{abstract}

Palabras clave: Screening; Enzima; Bacillus; Biotecnología.

\title{
1. Introdução
}

A biomassa vegetal é composta principalmente por celulose, hemicelulose e lignina, sendo a celulose o constituinte mais abundante da parede celular vegetal. A celulose é um homo-polissacarídeo composto por unidades repetidas de glicose ligadas por ligações $\beta$-1,4-glucosídicas e tem sido explorado como uma fonte rica em carbono para a produção de produtos químicos de valor agregado (Behera et al., 2017).

A hidrólise complete da celulose em açucares simples é obtida pela ação sinérgica das celulases, que compreende três classes distintas de enzimas: endoglucanases, celobiohidrolases (ou exobiohidrolases) e $\beta$-glucosidases. As endoglucanases hidrolisam ligações $\beta$-glicosídicas internas na cadeia da celulose, gerando oligossacarídeos com novas extremidades não redutoras; as exoglucanases atuam nas extremidades redutoras ou não redutoras dos oligossacarídeos, liberando a celobiose. A celobiose é posteriormente decomposta em glicose pelas $\beta$-glucosidases.

As celulases são aplicadas em diversos setores das indústrias, como: (1) indústria de papel e celulose, por meio da degradação de material lignocelulósico ou branqueamento de madeira e celulose (Dienes et al., 2004); (2) tratamento de resíduos e indústria de detergentes, melhorando a ação de limpeza; (3) indústria têxtil, por meio do biopolimento das fibras têxteis e do aprimoramento da qualidade dos tecidos; (4) alimentação animal, melhorando a digestão da alimentação e a qualidade da absorção (Kuhad et al., 2011); (5) processamento de alimentos, atuando na extração e clarificação da fruta durante a produção do suco (Bhat, 2000); (6) sacarificação enzimática para produção de bioethanol, estratégia que reduz os impactos ambientais e energéticos (Gupta et al., 2011).

Vários organismos, como bactérias, fungos, protozoários, nematóides e alguns artrópodes, são capazes de produzir celulase. A maioria das enzimas industriais tem sido derivada de microrganismos, uma vez que enzimas microbianas são mais vantajosas para a indústria porque podem ser produzidas em grandes quantidades por técnicas de fermentação, assim como genes que codificam enzimas podem ser facilmente modificados para otimizar o processo.

O objetivo do estudo foi isolar e identificar bactérias produtoras de celulase, e caracterizar parcialmente as enzimas quanto às características desejáveis para aplicação industrial.

\section{Metodologia}

O presente trabalho trata-se de uma pesquisa laboratorial, quantitativa. As amostras de solo foram coletadas em três diferentes áreas cobertas por vegetação natural, em ambientes preservados do bioma Cerrado, em Uberaba/Minas Gerais, Brasil. 
Os procedimentos de acondicionamento e processamento das amostras foram realizados no Laboratório de Microbiologia da Universidade Federal do Triângulo Mineiro, em Uberaba - Minas Gerais.

\section{Isolamento e triagem de bactérias produtoras de celulase}

As amostras de solo foram coletadas assepticamente a uma profundidade de $10 \mathrm{~cm}$. De cada amostra, $1 \mathrm{~g}$ de solo foi suspendido em $9 \mathrm{~mL}$ de solução salina estéril ( $\mathrm{NaCl} 0.85 \%)$, agitado por $1 \mathrm{~min}$, seguida de $1 \mathrm{~h}$ de repouso em temperatura ambiente. Suspensões de $0,1 \mathrm{~mL}$ foram espalhadas em meio ágar carboximetilcelulose $(\mathrm{pH} 7)$, contendo $0,2 \%$ de extrato de levedura, $0,1 \%$ de $\mathrm{KH}_{2} \mathrm{PO}_{4}, 0,5 \%$ de $\mathrm{MgSO}_{4}, 0,5 \%$ de carboximetilcelulose (CMC) e $2 \%$ de ágar (Apun et al., 2000).

As placas foram incubadas a $37^{\circ} \mathrm{C}$, em condições de aerobiose e microaerofilia. Após 24-48 h, as placas foram cobertas com solução vermelho congo $(1 \mathrm{mg} / \mathrm{mL})$ por $10 \mathrm{~min}$ e, em seguida, lavadas com solução de $\mathrm{NaOH}(1 \mathrm{M})$. As linhagens celulolíticas apresentaram zonas claras ao redor das colônias indicando a degradação do substrato (Teather and Wood, 1982).

Bactérias celulolíticas foram selecionadas e transferidas para novas placas com meio ágar CMC para confirmação da atividade enzimática e purificação das colônias. As culturas puras foram submetidas à coloração de Gram e preservadas em $20^{\circ} \mathrm{C}$ em meio BHI contendo $20 \%$ de glicerol.

O Índice Enzimático (EI), que consiste na razão entre o diâmetro do halo de degradação do substrato pelo diâmetro da colônia bacteriana, foi utilizado para selecionar os isolados com maior potencial de produção de celulases extracelulares (Hankin and Anagnostakis, 1975). Bactérias celulolíticas apresentando EI $\geq 1$ foram selecionadas para os experimentos subsequentes.

\section{Produção de celulases extracelulares e perfil de crescimento bacteriano}

Culturas bacterianas em fase estacionária (1\% de inóculo) foram transferidas para caldo CMC (mesma composição descrita, mas sem ágar) e incubadas a $37^{\circ} \mathrm{C}$, em aerobiose ou microaerofilia, por até $96 \mathrm{~h}$. A cada $24 \mathrm{~h}$, foram coletadas amostras para determinação da densidade óptica (600 nm; spectrophotometer UV-1600 -Pró-Análise) e para determinação da atividade celulolítica. A cultura foi centrifugada $(12000 \mathrm{~g}, 15 \mathrm{~min})$, as células foram descartadas, e o sobrenadante foi usado como extrato bruto. A atividade celulolítica foi determinada por ensaio de difusão em meio sólido, no qual as preparações de extrato bruto foram adicionadas aos poços feitos em ágar $\mathrm{CMC}$. As placas foram incubadas a $37^{\circ} \mathrm{C}$, em aerobiose ou microaerofilia, e a atividade celulolítica foi avaliada pela presença de zonas claras ao redor dos poços.

\section{Ensaio de atividade de celulase}

A quantificação das celulases produzidas pela bactéria selecionadas (crescimento de 72h) foi realizada medindo-se o açúcar redutor liberado pela reação no meio CMC, utilizando o método de Sacarificação (Miller, 1959). A absorbância foi medida a $540 \mathrm{~nm}$ e a quantidade de açúcar redutor foi calculada de acordo com uma curva padrão de glicose $(0.5-2.5 \mu \mathrm{mol} / \mathrm{mL}$ and 2-10 $\mu \mathrm{mol} / \mathrm{mL}$ ). Uma unidade (U) de atividade celulolítica foi definida como a quantidade de enzima que libera $1 \mu \mathrm{mol} \mathrm{de}$ açúcar redutor (glicose) por minute de reação. Todos os ensaios foram realizados em triplicata.

\section{Análise parcial da sequência de 16S rRNA}

O sequenciamento parcial do gene $16 \mathrm{~S}$ rRNA foi utilizado para identificação dos isolados celulolíticos. O DNA total foi extraído usando o método do fenol-clorofórmio. A integridade do DNA foi verificada por eletroforese em gel de agarose (0,8\%), usando tampão TAE 1 X (base Tris 40, ácido acético $20 \mathrm{mM}$ e EDTA $1 \mathrm{mM}$ - pH 8.0), e brometo de etídio $(0.2 \mu \mathrm{g} / \mathrm{mL})$ para a coloração do gel. A visualização do DNA foi realizada sob luz ultravioleta (UV). A concentração e a pureza do DNA 
foram avaliadas por espectrofotômetro NanoDrop (Thermo Scientific). Todas as amostras foram diluídas para $50 \mathrm{ng} / \mu \mathrm{L} \mathrm{e}$ armazenadas a $-20^{\circ} \mathrm{C}$.

O gene 16S rRNA foi amplificado usando o par de primers universais 27F (AGAGTTTGATCMTGGCTCA) e 1492R (TACGGYTACCTTGTTACGAC). As reações de amplificação foram realizadas no termociclador de DNA GeneAmp PCR System 9700 (Applied Biosystems) e as condições incluíram uma etapa de desnaturação inicial a $95^{\circ} \mathrm{C}$ por 5 min, seguida de 35 ciclos de desnaturação a $95^{\circ} \mathrm{C}$ por $30 \mathrm{~s}$, anelamento a $60^{\circ} \mathrm{C}$ por $30 \mathrm{~s}$, e extensão do primer a $72^{\circ} \mathrm{C}$ por 1 min. $\mathrm{O}$ ciclo de amplificação foi seguido por uma extensão final a $72^{\circ} \mathrm{C}$ por 7 min. A amplificação por PCR foi realizada em um volume de reação final de $25 \mu \mathrm{L}$, e a mistura de reação continha $17.325 \mu \mathrm{L}$ de água milli-Q, $2.5 \mu \mathrm{L}$ de tampão $10 \mathrm{X}, 1.25 \mu \mathrm{L}$ de $\mathrm{MgCl}_{2}$ $(50 \mathrm{mM}), 1 \mu \mathrm{L}$ do primer $\mathrm{F}(10 \mathrm{pM} / \mu \mathrm{L}), 1 \mu \mathrm{L}$ do primer $\mathrm{R}(10 \mathrm{pM} / \mu \mathrm{L}), 1 \mu \mathrm{L}$ da amostra de DNA $(50 \mathrm{ng} / \mu \mathrm{L}), 0.625 \mu \mathrm{L}$ do mix de dNTPs (10 mM) e $0.3 \mu \mathrm{L}$ de Taq DNA Polimerase (5 U/ $\mu \mathrm{L}$ ) (Thermo Scientific). Os produtos de PCR amplificados foram analisados por eletroforese em gel de agarose $(1,2 \%)$, corados com brometo de etídio $(0.2 \mu \mathrm{g} / \mathrm{mL})$ e visualizados sob luz UV.

Os amplicons foram purificados diretamente do produto de PCR utilizando o kit Invisorb® Fragment CleanUp (Stratec Molecular), seguindo as instruções do fabricante. Os amplicons foram quantificados por espectrofotômetro NanoDrop e sequenciados pelo método de terminação de cadeia (Método Sanger). Duas reações foram realizadas, utilizando os primers forward e reverse. Todas as sequências foram editadas manualmente e alinhadas com aquelas disponíveis na base de dados do GenBank (NCBI), utilizando o algoritmo BLASTn, e depositadas na base de dados do GenBank.

\section{Análise Filogenética}

O alinhamento de múltiplas sequências foi feito usando o programa Clustal W. A árvore filogenética foi reconstruída com o programa MEGA 7.0 no qual foi aplicado o método de Máxima Verossimilhança. Brevibacillus brevis YNP-1 foi usado como grupo externo e a análise Bootstrap (1000 réplicas) com base no modelo Kimura-2-parameter foi utilizado para ter uma estimativa confiável da árvore filogenética.

\section{Caracterização parcial das celulases}

As celulases produzidas pelo isolados selecionados foram caracterizadas de acordo com o $\mathrm{pH}$, temperatura e a presença de íons metálicos na reação. $\mathrm{O}$ ensaio da atividade da celulase foi realizado em condições padrão, mas variando o pH, a temperatura ou a presença de íons metálicos.

$\mathrm{O}$ efeito dos diferentes $\mathrm{pHs}$ na atividade de celulase foi testado utilizando meio $\mathrm{CMC}$ em diferentes valores de $\mathrm{pH}$ ( 2 a 12), definidos utilizando soluções tampão apropriadas (para pH 2: cloreto de potássio 0,2 M-HCl; pH 4 e 6: acetato de sódio 0,5 M; pH 7 e 8: fosfato de sódio 0,05 M; pH 10: Tris- $\mathrm{HCl}$ 0,05 M; pH 12: fosfato de sódio 0,1 M-NaOH). O impacto da temperatura na atividade de celulase foi testado incubando a mistura de reação em diferentes temperaturas $\left(10\right.$ a $80^{\circ} \mathrm{C}$, com aumento de $10^{\circ} \mathrm{C}$ ), sob condições padrão.

O efeito dos íons metálicos na atividade de celulase foi investigado utilizando $\mathrm{CaCl}_{2}, \mathrm{MgCl}_{2}, \mathrm{NaCl}$ e $\mathrm{FeSO}_{4}(5 \mathrm{mM})$. $\mathrm{O}$ extrato bruto foi incubado por 5 minutos em temperatura ambiente com diferentes íons metálicos, e a atividade da celulase foi mensurada utilizando condições ótimas de $\mathrm{pH}$ e temperatura para cada enzima, definidos em experimentos prévios.

Em cada caso, a maior atividade enzimática observada foi considerada como 100\%, e a atividade relativa foi calculada para as outras condições como a porcentagem de atividade em proporção à maior atividade. 


\section{Análise Estatística}

A análise de variância (ANOVA) unilateral com o teste de comparações múltiplas de Dunnett $(\mathrm{p}<0.05)$ foi realizado usando o software GraphPad Prism versão 7.04.

\section{Resultados e Discussão}

$\mathrm{O}$ avanço da biotecnologia industrial e o aumento da demanda por enzimas têm impulsionado a busca por novas linhagens microbianas produtoras de enzimas. Bactérias que habitam o Cerrado podem ser uma alternativa promissora para suprir essa demanda, já que o Cerrado brasileiro é uma região rica em biodiversidade e pouco explorada.

No presente trabalho foi realizada a bioprospecção e a identificação de bactérias produtoras de celulase isoladas do solo coletado no bioma Cerrado brasileiro, bem como uma caracterização parcial das enzimas produzidas. No total, 84 colônias bacterianas foram isoladas em meio ágar CMC. Após subcultura em ágar CMC e coloração com solução vermelho congo, a atividade da celulase foi confirmada em 14 isolados: seis isolados foram obtidos da amostra de solo 1, quatro isolados da amostra do solo 2 e outros quatro isolados do solo 3. Em relação às condições atmosféricas, quatro linhagens foram isoladas em aerobiose e $10 \mathrm{em}$ microaerofilia. Todas as bactérias celulolíticas eram Gram-positivas e em forma de bastonete. O índice enzimático variou de 0,67 (isolado AD-8) a 1,25 (isolado MP-8), e 10 isolados produtores de celulase apresentaram EI $\geq 1,0$ (Tabela 1; Figura 1).

Tabela 1: Caracterização de bactérias produtoras de celulase isoladas do bioma Cerrado brasileiro, no Triângulo Mineiro. Amostra de isolamento. Coloração de Gram, morfologia, atmosfera de isolamento e índice enzimático (EI) são mostrados.

\begin{tabular}{|c|c|c|c|c|c|}
\hline $\begin{array}{l}\text { Amostra de } \\
\quad \text { Solo }\end{array}$ & $\begin{array}{c}\text { Isolado } \\
\text { Bacteriano }\end{array}$ & $\begin{array}{c}\text { Coloração de } \\
\text { Gram }\end{array}$ & Morfologia & $\begin{array}{c}\text { Atmosfera de } \\
\text { Isolamento }\end{array}$ & $\begin{array}{l}\text { Índice Enzimático } \\
\text { (EI) }\end{array}$ \\
\hline \multirow{6}{*}{1} & AB-8 & Positivo & Bacilo & Aerobiose & 0.67 \\
\hline & AB-9 & Positivo & Bacilo & Aerobiose & 1.00 \\
\hline & AB-1 & Positivo & Bacilo & Aerobiose & 1.00 \\
\hline & MB-2 & Positivo & Bacilo & Microaerofília & 1.00 \\
\hline & MB-3 & Positivo & Bacilo & Microaerofília & 1.00 \\
\hline & MB-22 & Positivo & Bacilo & Microaerofília & 1.00 \\
\hline \multirow{4}{*}{2} & MP-6 & Positivo & Bacilo & Microaerofília & 0.87 \\
\hline & MP-7 & Positivo & Bacilo & Microaerofília & 1.20 \\
\hline & MP-8 & Positivo & Bacilo & Microaerofília & 1.25 \\
\hline & MP-11 & Positivo & Bacilo & Microaerofília & 0.80 \\
\hline \multirow{4}{*}{3} & AE-1 & Positive & Bacilo & Aerobiose & 0.70 \\
\hline & ME-1 & Positive & Bacilo & Microaerofília & 1.00 \\
\hline & ME-2.1 & Positive & Bacilo & Microaerofília & 1.00 \\
\hline & ME-2 & Positive & Bacilo & Microaerofília & 1.00 \\
\hline
\end{tabular}

Fonte: Autores. 
Figura 1: Atividade celulolítica dos isolados bacterianos com EI $\geq 1.0$. O teste celulolítico, utilizando CMC como substrato, foi realizado após 72 horas de incubação. A atividade enzimática foi expressa em U/mL. Os resultados apresentados são as médias de análises em triplicata e as barras de erros indicam \pm DPs das médias.

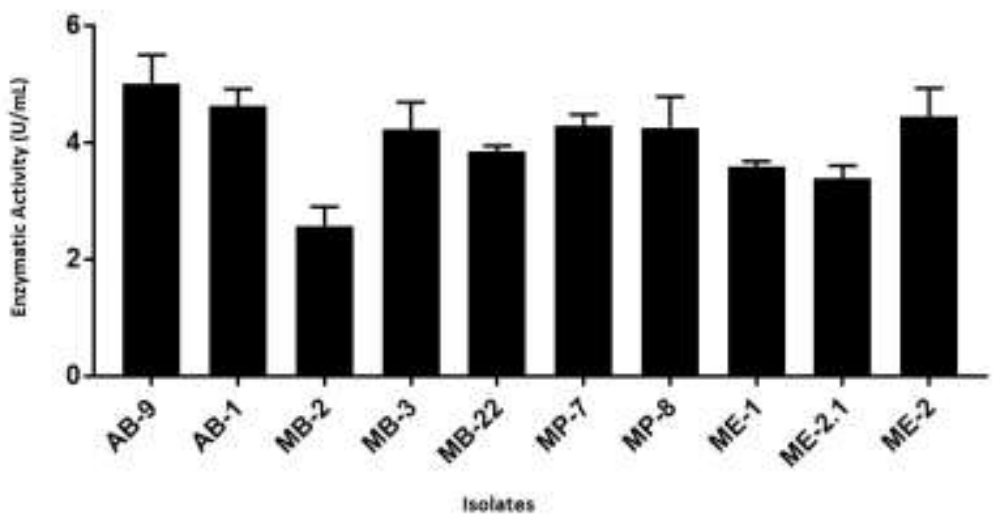

Fonte: Autores.

O crescimento bacteriano foi monitorado durante $96 \mathrm{~h}$ de incubação, e a produção de celulases extracelulares foi avaliada a cada 24h, em meio sólido contendo CMC. Todos os isolados celulolíticos $(\mathrm{n}=10)$ apresentaram padrão de crescimento semelhante, atingindo a fase estacionária entre 72 h e 96 h de crescimento (Tabela 2). A atividade celulolítica foi detectada desde as primeiras $24 \mathrm{~h}$ de crescimento bacteriano, e foi mantida até $96 \mathrm{~h}$ de incubação. Apenas o isolado AB-1 apresentou atividade celulolítica significativa após 96 h de crescimento bacteriano (Tabela 2). Tiwari R et al. (2017) relataram perfis de crescimento semelhantes para cepas de B. subtilis e produção máxima de celulases após $72 \mathrm{~h}$ de cultura.

Tabela 2: Produção de celulases durante o crescimento bacteriano.

\begin{tabular}{|c|c|c|c|c|c|c|c|c|}
\hline \multirow{2}{*}{$\begin{array}{c}\text { Bactéria } \\
\text { Celulolítica }\end{array}$} & \multicolumn{4}{|c|}{ Absorbância (600 nm) } & \multicolumn{4}{|c|}{$\begin{array}{l}\text { Diâmetro das zonas claras em torno dos } \\
\text { poços de ágar }(\mathbf{n m})\end{array}$} \\
\hline & $24 \mathrm{~h}$ & $48 \mathrm{~h}$ & $72 \mathrm{~h}$ & $96 \mathrm{~h}$ & $24 \mathrm{~h}$ & $48 \mathrm{~h}$ & $72 \mathrm{~h}$ & $96 \mathrm{~h}$ \\
\hline AB-9 & 0.384 & 0.506 & 0.876 & 0.872 & 23 & 23 & 20 & 20 \\
\hline AB-1 & 0.037 & 0.127 & 0.590 & 0.497 & 5 & 5 & 5 & 22 \\
\hline MB-2 & 0.278 & 0.546 & 0.698 & 0.810 & 25 & 25 & 20 & 19 \\
\hline MB-3 & 0.239 & 0.497 & 0.582 & 0.786 & 23 & 27 & 20 & 20 \\
\hline MB-22 & 0.283 & 0.582 & 0.844 & 0.884 & 19 & 21 & 17 & 19 \\
\hline MP-7 & 0.257 & 0.538 & 0.620 & 0.720 & 22 & 23 & 17 & 19 \\
\hline MP-8 & 0.291 & 0.577 & 0.654 & 0.798 & 21 & 22 & 20 & 19 \\
\hline ME-1 & 0.299 & 0.552 & 0.716 & 0.858 & 23 & 23 & 18 & 20 \\
\hline ME-2.1 & 0.200 & 0.586 & 0.694 & 0.886 & 21 & 23 & 18 & 20 \\
\hline ME-2 & 0.207 & 0.495 & 0.580 & 0.674 & 22 & 28 & 15 & 21 \\
\hline
\end{tabular}

Fonte: Autores.

Após $72 \mathrm{~h}$ de cultura bacteriana, a atividade celulolítica foi medida e variou de $2.575 \mathrm{U} / \mathrm{mL}$ (isolado MB-2) a 5.0 $\mathrm{U} / \mathrm{mL}$ (isolado AB-9). Com base na atividade celulolítica, os cinco isolados produtores de celulase mais promissores, AB-9 
(5.0 U/mL), AB-1 (4.630 U/mL), MB-3 (4.236 U/mL), MP-7 (4.282 U/mL) e ME-2 (4.444 U/mL) (Figura 2), foram selecionados para os experimentos subsequentes.

Resultados semelhantes foram encontrados por Paudel YP (2015) e Qin W (2015) com Bacillus sp. K1, que atingiu a maior produção de carboximetilcelulase (CMCase) $(5.21 \mathrm{U} / \mathrm{mL})$ após $72 \mathrm{~h}$, com entrada em fase estacionária. $\mathrm{O}$ crescimento e o perfil enzimático podem variar de acordo com a espécie bacteriana e as condições de cultivo. Diferentes períodos de incubação têm sido relatados para obter a melhor atividade celulolítica, como $48 \mathrm{~h}$ e $60 \mathrm{~h}$ para Bacillus sp. (Goyal V et al., 2014), 144 h para Geobacillus (Potprommanee L et al., 2017) ou mesmo períodos de incubação mais longos, como cinco dias de crescimento para alguns isolados de Bacillus (Abd Elhameed E et al., 2020).

De acordo com o sequenciamento parcial do gene 16S rRNA, os cinco isolados produtores de celulase mais promissores foram identificados como pertencentes ao gênero Bacillus, apresentando alta identidade ( $\geq 90 \%)$ com quatro diferentes espécies: Bacillus siamensis PDA10 (isolado AB-9), Bacillus toyonensis BCT-7112 (isolado AB-1), Bacillus methylotrophicus BMB205 (isolado MB-3 and MP-7) e Bacillus drentensis NBRC102427 (isolado ME-2). A sequências foram depositadas no banco de dados de sequências sob os números de acesso MH381824 (B. siamensis AB-9), MH381825 (B. toyonensis AB-1), MH381826 (B. methylotrophicus MB-3), MH381827 (B. methylotrophicus MP-7), e MH381828 (B. drentensis ME-2).

A reconstrução da árvore filogenética mostrou que B. siamensis AB-9, B. methylotrophicus MB-3 e $B$. methylotrophicus MP-7 foram relacionados a $B$. toyonensis AB-1, confirmando que pertencem a grupos filogenéticos próximos; enquanto B. drentensis ME-2 está menos relacionado aos outros isolados (Figura 2).

Figura 2: Árvore filogenética molecular dos cinco isolados bacterianos com maior atividade celulolítica. A árvore deduzida das sequências de rRNA 16S foi reconstruída com MEGA 7.0 pelo método de Máxima Verossimilhança baseado no modelo Kimura-2-parameter. Os comprimentos dos ramos medem o número de substituições e a árvore de consenso de bootstrap inferida de 1000 réplicas. Brevibacillus brevis YNP-1 foi usado como grupo externo. A escala abaixo mostra a substituição por site.

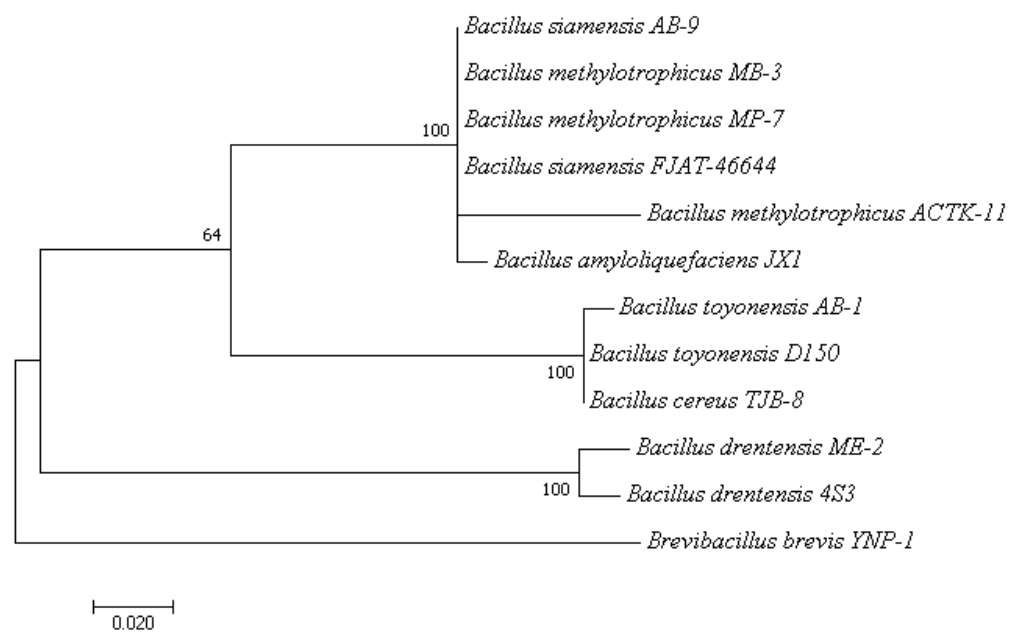

Fonte: Autores.

Em relação aos fatores físico-químicos que podem induzir ou inibir a atividade enzimática, o pH teve influência relevante na atividade das celulases produzidas. O extrato enzimático obtido de B. siamensis AB-9 foi mais estável nos diferentes valores de $\mathrm{pH}$, mantendo sua atividade celulolítica em pH 2 a 8 ( $>$ > 0.05) (Figura 3-A). As enzimas produzidas por B. toyonensis AB-1 e B. methylotrophicus MP-7 apresentaram melhores atividades em pH 7 e 8 ( $p>0.05)$. As enzimas 
produzidas por B. methylotrophicus MB-3 e B. drentensis ME-2 foram mais ativas em pH 7, embora considerável atividade de celulase em pH 8 também tenha sido detectada para ambos os extratos (78\% e 59\%, respectivamente) (Figura 3-D, E).

A atividade celulolítica máxima em $\mathrm{pH}$ neutro a alcalino foi descrita para B. methylotrophicus $\mathrm{S} 2\left(\mathrm{pH} 7.5\right.$, a $\left.55^{\circ} \mathrm{C}\right)$ (Niu et al., 2016), Bacillus sp. (pH 7-8, a 37 ${ }^{\circ} \mathrm{C}$ ) (Mukhtar et al., 2019), Bacillus sp. (pH 7, a 40 ${ }^{\circ} \mathrm{C}$ ) (Elhameed et al., 2020) e $B$. thuringiensis ( $\mathrm{pH} \mathrm{8}$, a $60^{\circ} \mathrm{C}$ ) (Awasthi MK et al., 2018), corroborando com os resultados obtidos no presente estudo. A celulases alcalinas podem ser adicionadas como aditivos detergentes ajudando a iluminar as cores, amaciar os tecidos e remover a sujeira; tais enzimas também funcionam para melhorar a resistência das formulações de polpa de papel nas indústrias de papel (Gupta et al., 2015).

Celulases bacterianas com atividade máxima em $\mathrm{pH}$ ácido também foram descritas, como $\mathrm{pH} 5.5$ para B. subtilis BY3 (Meng et al., 2014) e pH 4 para Bacillus sonorensis HSC7 (Azadian F et al., 2017). Celulases de natureza alcalina foram relatadas para Clostridium thermocellum Z-7026 (pH ótimo de 9) (Zvereva EA et al., 2006) e Bacillus sp. KSM-N252 (pH ótimo de 10) (Endo et al., 2001).

A atividade hidrolítica das celulases pode variar de acordo com a temperatura da reação, e uma grande variação tem sido descrita para o gênero bacteriano Bacillus em relação à temperatura ótima para a atividade da celulase. No geral, extratos contendo celulases obtidas no presente estudo mostraram boa atividade em uma ampla faixa de temperatura, mantendo a atividade enzimática acima de 40\% (quando comparada com a atividade na condição padrão) (Figura 3-F a J).

B. siamensis AB-9 e B. toyonensis AB-1 produziram celulases que eram estáveis e igualmente ativas de 10 a $80^{\circ} \mathrm{C}(\mathrm{p}$ $>0.05$ ). O extrato enzimático obtido de B. methylotrophicus MP-7 apresentou maior atividade celulolítica em temperatura de $10-30^{\circ} \mathrm{C}$ e $60-70^{\circ} \mathrm{C}(\mathrm{p}>0.05)$, enquanto para B. methylotrophicus $\mathrm{MB}-3$ foi obtida máxima atividade celulolítica na faixa de 20 a $70^{\circ} \mathrm{C}(\mathrm{p}>0.05)$ (Figura 3-H, I).

As celulases produzidas por $B$. drentensis ME-2 foram as mais influenciadas pela temperatura: maior atividade enzimática foi observada a $60^{\circ} \mathrm{C}$, enquanto em outras temperaturas foram observadas reduções significativas na atividade hidrolítica ( $\mathrm{p}<0.05$ ), e a atividade enzimática variou de $58 \%$ a $40^{\circ} \mathrm{C}$ para $100 \%$ a $60^{\circ} \mathrm{C}$ (Figura $3-\mathrm{J}$ ). algumas celulases são descritas na literatura com atividade ótima a $50-60^{\circ} \mathrm{C}$, como as produzidas por B. amyloliquefaciens AK9 (Irfan et al., 2017) e B. subtilis BS-5 (Wu et al., 2018).

A estabilidade térmica em alta $\left(60^{\circ} \mathrm{C}\right)$ e baixa $\left(30-50^{\circ} \mathrm{C}\right)$ temperatura é um recurso desejável para a aplicação industrial de celulases, pois economiza energia da reação (Ma et al., 2020), e permite a interação com outras enzimas, tais como aquelas que degradam lignina $\left(\mathrm{a} 30^{\circ} \mathrm{C}\right.$ ) e xilanases (a 50-60 ${ }^{\circ} \mathrm{C}$ ) (Liu et al., 2019).

A necessidade de cofatores varia entre as enzimas, e o mesmo íon pode atuar de forma oposta na reação. Existem relatos de celulases que são metaloenzimas e dependem de íons como $\mathrm{Ca}^{2+}, \mathrm{Fe}^{2+}, \mathrm{Mn}^{2+}$ e $\mathrm{Co}^{2+}$ (Cheng et al., 2016); outras celulases podem ser inibidas por $\mathrm{Ca}^{2+}, \mathrm{Mn}^{2+} \mathrm{e} \mathrm{Co}^{2+}$ (Huang et al., 2015); ou podem até ser indiferentes à presença de metais, como K, $\mathrm{Zn}^{2+}, \mathrm{Mg}^{2+}$ e $\mathrm{Na}^{+}$(Asha et al., 2012).

No presente estudo, nenhum dos íons metálicos avaliados teve influência significativa na atividade das celulases ( $\mathrm{p}$ > 0.05) (Figura 3-K a O). Zarafeta et al. (2016) relataram resultados similares para Thermoanaerobacterium sp. GH5 produtoras de CMCase, em que os íons $\mathrm{Ca}^{2+}, \mathrm{Mg}^{2+}$ e $\mathrm{Na}^{+}$não influenciaram a atividade enzimática, enquanto o íon $\mathrm{Fe}^{2+}$ foi capaz de inibir a atividade enzimática. A mesma estabilidade na presença de cátions divalentes foi relatada para celulases produzidas por Bacillus subtilis $\mathrm{BC} 1$, em que os íons $\mathrm{Ca}^{2+}$ e $\mathrm{Co}^{2+}$ íns induziram um aumento na atividade catalítica (Dehghanikhah et al., 2020). 
Figura 3: Efeito do $\mathrm{pH}(\mathrm{A}-\mathrm{E})$, temperatura (F-J) e íons metálicos (K-O) na atividade celulolítica de bactérias do solo. Atividade enzimática dos extratos brutos obtidos de B. siamensis AB-9 (A, F, K), B. toyonensis AB-1 (B, G, L), B. methylotrophicus MP-7 (C, H, M), B. methylotrophicus MP-3 (D, I, N) e B. drentensis ME-2 (E, J, O) foram avaliados em um condições variadas de $\mathrm{pH}\left(2 \mathrm{a} 12\right.$, a $55^{\circ} \mathrm{C}$ (gráficos $\mathrm{A}$ a $\left.\mathrm{E}\right)$ ); de temperatura $\left(10\right.$ a $80^{\circ} \mathrm{C}$, usando tampão fosfato de sódio $(0,05$ M, pH 7,0 (gráficos F a J)); e na presença de íons $\left(\mathrm{Ca}^{2+}, \mathrm{Mg}^{2+}, \mathrm{Na}^{+}\right.$e $\mathrm{Fe}^{2+}$, em condições ótimas ( $\mathrm{pH}$ e temperatura) (gráficos $\mathrm{K}$ a O)). A maior atividade enzimática foi considerada $100 \%$, e para as demais foi calculada a atividade relativa (\%). Os resultados apresentados são as médias de duas repetições biológicas e as barras de erros indicam \pm DPs das médias. Os asteriscos indicam diferenças significativas $(\mathrm{p}<0,05)$.
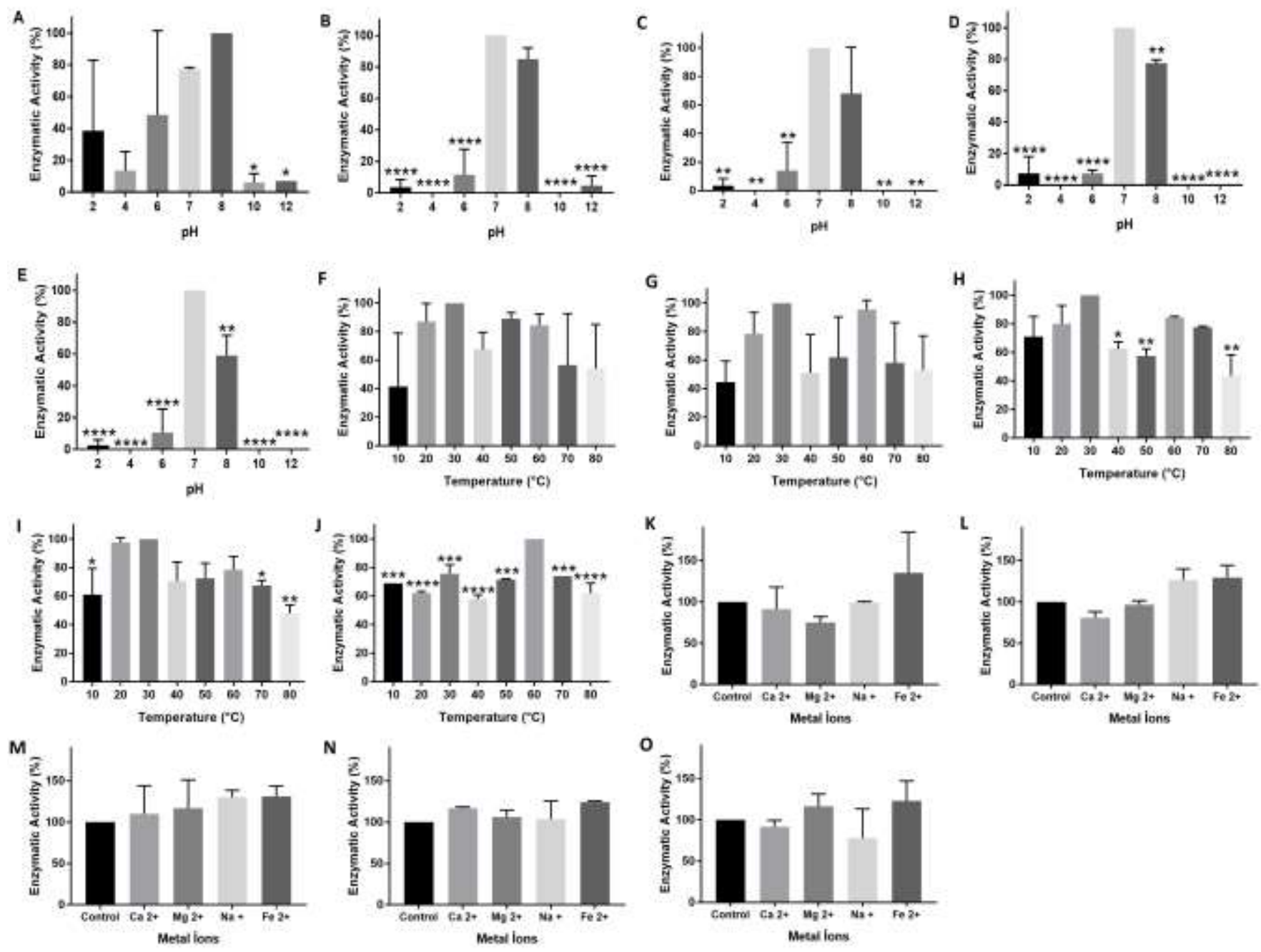

Fonte: Autores.

\section{Conclusão}

O presente trabalho descreve, pela primeira vez, o isolamento de bactérias celulolíticas a partir de amostras de solo obtidas de um bioma preservado no Cerrado brasileiro, na região do Triângulo Mineiro. As enzimas avaliadas apresentam estabilidade em diferentes valores de $\mathrm{pH}$ e ampla faixa de temperatura, não sendo influenciadas pela presença de íons metálicos. Dessa forma, apresentam potencial promissor para futuras aplicações biotecnológicas.

Estudos adicionais devem ser realizados visando a caracterização completa das enzimas celulolíticas identificadas, bem como a produção em maior escala. 


\section{Referências}

Apun, K., Jong, B. C., \& Salleh, M .A. (2000). Screening and isolation of a cellulolytic and amylolytic Bacillus from sago pith waste. Journal of General and Applied Microbiology, 46 (5), 263-267.

Asha, B. M., Revathi, M., Yadav, A., \& Sakthivel, N. (2012). Purification and characterization of a thermophilic cellulase from a novel cellulolytic strain. Paenibacillus barcinonensis. Journal of Microbiology and Biotechnology, 22 (11), 1501-1509.

Awasthi, M. K., Wong, J. W. C., Kumar, S., Awasthi, S.K., Wang, Q., Wang, M., Ren, X., Zhao, J., Chen, H., \& Zhang, Z. (2018). Biodegradation of food waste using microbial cultures producing thermostable $\alpha$-amylase and cellulase under different pH and temperature. Bioresource Technology, $248,160-170$.

Azadian, F., Badoei-dalfard, A., Namaki-Shoushtari, A., Karami, Z., \& Hassanshahian, M. (2017). Production and characterization of an acido-thermophilic, organic solvent stable cellulase from Bacillus sonorensis HSC7 by conversion of lignocellulosic wastes. Journal of Genetic Engineering and Biotechnology, $15(1), 187-196$

Behera, B. C., Sethi, B. K., Mishra, R. R., Dutta, S. K., \& Thatoi, H. N. (2017). Microbial cellulases - Diversity \& biotechnology with reference to mangrove environment: A review. Journal of Genetic Engineering and Biotechnology, 15 (1), 197-210.

Bhat, M. K. (2000). Cellulases and related enzymes in biotechnology. Biotechnology Advances, 18 (5), $355-383$.

Cheng, J., Huang, S., Jiang, H., Zhang, Y., Li, L., Wang, J., \& Fan, C. (2016). Isolation and characterization of a non-specific endoglucanase from a metagenomic library of goat rumen. World Journal of Microbiology and Biotechnology, 32 (1), 12.

Dehghanikhah, F., Shakarami, J., \& Asoodeh, A. (2020). Purification and biochemical characterization of alkalophilic cellulase from the symbiotic Bacillus subtilis BC1 of the leopard moth, zeuzera pyrina (L.) (Lepidoptera: Cossidae). Current Microbiology, 77 (7), $1254-1261$.

Dienes, D., Egyházi, A., \& Réczey, K. (2004). Treatment of recycled fiber with Trichoderma cellulases. Industrial Crops Products, 20 (1), $11-21$.

Elhameed, E. A., Sayed, A.R.M., Radwan, T. E. E., \& Hassan, G. (2020). Biochemical and molecular characterization of five Bacillus isolates displaying remarkable carboxymethyl cellulase activities. Current Microbiology, 77 (10), 3076-3084.

Endo, K., Hakamada, Y., Takizawa, S., Kubota, H., Sumitomo, N., Kobayashi, T., \& Ito, S. (2001). A novel alkaline endoglucanase from an alkaliphilic Bacillus isolate: enzymatic properties, and nucleotide and deduced amino acid sequences. Applied Microbiology and Biotechnology, 57 (1-2), 109-16.

Goyal, V., Mittal, A., Bhuwal, A. K., Singh, G., Yadav, A., \& Aggarwal, N. K. (2014). Parametric optimization of cultural conditions for carboxymethyl cellulase production using pretreated rice straw by Bacillus sp. 313SI under stationary and shaking conditions. Biotechnology Research International, 2014, 651839 .

Gupta, M., Sharma, M., \& Singh, S. (2015). Enhanced production of cellulase from Bacillus licheniformis K-3 with potential for saccharification of rice straw. Energy Technology, 3, 216-224.

Gupta, R., Khasa, Y. P., \& Kuhad, R. C. (2011). Evaluation of pretreatment methods in improving the enzymatic saccharification of cellulosic materials. Carbohydrate Polymers, 84 (2011), 1103-1109.

Hankin, R., \& Anagnostakis, S. L. (1975). The use of solid media for detection of enzymes production by fungi. Mycology, 67 (3), $596-607$.

Huang, S., Deng, G., Yang, Y., Wu, Z., \& Wu, L. (2015). Optimization of endoglucanase production from a novel bacterial isolate, Arthrobacter sp. HPG166 and characterization of its properties. Brazilian Archives of Biology Technology, 58 (5), 692-701.

Irfan, M., Tayyab, A., Hasan, F., Khan, S., Badshah, M., \& Shah, A. A. (2017). Production and characterization of organic solvent-tolerant cellulase from Bacillus amyloliquefaciens AK9 isolated from hot spring. Applied Biochemistry and Biotechnology, 182 (4), $1390-1402$.

Kuhad, R. C., Gupta, R., \& Singh, A. (2011). Microbial Cellulases and their industrial applications. Enzyme Research, $2011,280696$.

Liu, X., Jiang, Z., Liu, Y., You, X., Yang, S., \& Yan, Q. (2019). Biochemical characterization of a novel exo-oligoxylanase from Paenibacillus barengoltzii suitable for monosaccharification from corncobs. Biotechnology for Biofuels, 12, 190.

Ma, L., Aizhan, R., Wang, X., Yi, Y., Shan, Y., Liu, B., Zhou, Y., \& Lü, X. (2020). Cloning and characterization of low-temperature adapted GH5-CBM3 endo-cellulase from Bacillus subtilis 1AJ3 and their application in the saccharification of switchgrass and coffee grounds. AMB Express, 10 (1), 42.

Meng, F., Ma, L., Ji, S., Yang, W., \& Cao, B. (2014). Isolation and characterization of Bacillus subtilis strain BY-3, a thermophilic and efficient cellulaseproducing bacterium on untreated plant biomass. Letters Applied Microbiology, 59 (3), 306-312.

Miller, G. L. (1959). Use of dinitrosalicylic acid reagent for determination of reducing sugar. Analytical Chemistry, 31 (3), 426-428.

Mukhtar, S., Mehnaz, S., Mirza, M. S., \& Malik, K. A. (2019). Isolation and characterization of bacteria associated with the rhizosphere of halophytes (Salsola stocksii and Atriplex amnicola) for production of hydrolytic enzymes. Brazilian Journal of Microbiology, 50 (1), 85-97.

Niu, Q., Zhang, G., Zhang, L., Ma, Y., Shi, Q., \& Fu, W. (2016). Purification and characterization of a thermophilic 1,3-1,4- $\beta$-glucanase from Bacillus methylotrophicus S2 isolated from booklice. Journal of Bioscience and Bioengeneering, 121 (5), 503-508.

Paudel, Y. P., \& Qin, W. (2015). Characterization of novel cellulase-producing bacteria isolated from rotting wood samples. Applied Biochemical Biotechnology, 177 (5), 1186-98. 
Research, Society and Development, v. 10, n. 8, e34010817426, 2021

(CC BY 4.0) | ISSN 2525-3409 | DOI: http://dx.doi.org/10.33448/rsd-v10i8.17426

Potprommanee, L., Wang, X. Q., Han, Y. J., Nyobe, D., Peng, Y. P., Huang, Q., Liu, J. Y., Liao, Y. L., \& Chang, K. L. (2017). Characterization of a thermophilic cellulase from Geobacillus sp. HTA426, an efficient cellulose producer on alkali pretreated of lignocellulosic biomass. PLoS ONE, 12 (4), 0175004

Teather, R. M., \& Wood, P. J. (1982). Use of Congo red-polysaccharide interactions in enumeration and characterization of cellulolytic bacteria from the bovine rumen. Applied Environmental Microbiology, 43 (4), 777-780.

Tiwari, R., Singh, P. K., Singh, S., Nain, P. K. S., Nain, L., \& Shukla, P. (2017). Bioprospecting of novel thermostable $\beta$-glucosidase from Bacillus subtilis RA10 and its application in biomass hydrolysis. Biotechnology Biofuels, 10, 246.

Wu, B., Zheng, S., Pedroso, M. M., Guddat, L. W., Chang, S., He, B., \& Schenk, G. (2018). Processivity and enzymatic mechanism of a multifunctional family 5 endoglucanase from Bacillus subtilis BS-5 with potential applications in the saccharification of cellulosic substrates. Biotechnology for Biofuels, 11, 20.

Zarafeta, D., Kissas, D., Sayer, C., Gudbergsdottir, S. R., Ladoukakis, E., Isupov, M. N., Chatziioannou, A., Peng, X., Littlechild, J. A., Skretas, G., \& Kolisis, F. N. (2016). Discovery and characterization of a thermostable and highly halotolerant GH5 cellulase from an icelandic hot spring isolate. PLoS One, 11 (1), 0146454 .

Zvereva, E. A., Fedorova, T. V., Kevbrin, V. V., Zhilina, T. N., \& Rabinovich, M. L. (2006). Cellulase activity of a haloalkaliphilic anaerobic bacterium, strain Z-7026. Extremophiles, 10 (1), 53-60 